\title{
Frequency of Marijuana Use among Students in Sports and Medical Students at Two Universities in Bulgaria
}

\author{
Valentin Valtchev ${ }^{1}$, Petranka Chumpalova ${ }^{2}$ \\ ${ }^{1}$ Department of Physiology, National Sports Academy, Sofia, Bulgaria \\ ${ }^{2}$ Department Psychiatry and Medical Psychology, Medical University, Pleven, Bulgaria
}

\begin{abstract}
The aim of this study was to investigate the number of cases and the profiles of Bulgarian athletes and medical students who had occasionally been using cannabinoids throughout the period of 2014-2015. Material and Methods: There were studied 50 athletes from Sports University, Sofia and 50 medical students from Medical University, Pleven aged between 18 and 25 years. Material and methods: In our study included 240 randomly selected students at the Sports University and the Medical University in aged between 18 and 25 years. We have designed a questionnaire containing six closed questions. All participants completed self-administered questionnaire. Conclusions: In both groups, the use of marijuana is more common in men than in women. 41,7\% of athletes and 15,8 $\%$ of medical students have used marijuana in the past 12 months.
\end{abstract}

Keywords: athletes, marijuana, sports students, medical students

\section{Introduction}

The purpose of this study was to investigate the number of cases and the profiles of Bulgaria athletes who had occasionally been using marijuana or hashish throughout the period of 2014-2015.

The use of substances to increase athletic performance has occurred throughout the world since the appearance of sports competition in ancient Greece, the birth of the modern Olympic Games [1]. The products of Cannabis sativa, such as marijuana, hashish, hash oil, sensemilla and others, obtained from different parts of the plant, are considered to be the most popular illicit drug throughout the world. Historically, these products were already use in the Chinese Empire in $2700 \mathrm{BC}$ in the treatment of malaria and rheumatism $[2,4]$.

More than 400 different compounds, distributed by 18 chemical groups, were detected in different species of cannabis plants. The most important group is the cannabinoids, in which the substance delta-9tetrahydrocannabinol (THC) is the most significant compound, due to its psychoactive properties [3, 4].

The rate of absorption of the active component (THC) by the lungs is very high; consequently, immediate effects can occur depending on the dynamic of the smoking act: the duration and time interval of each inhalation, as well as the quantity of smoke inhaled [2, 3, 4]. When cannabis is smoked, the euphoric effects appear within minutes, peak in about 30 minutes, and last 2 to 4 hours. Some motor and cognitive effects last 5 to 12 hours [4].

The collective name given to the terpenes found in cannabis is cannabinoids. Most of the naturally occurring cannabinoids have now been identified, and three are the most abundant - cannabidiol (CBD), tetrahydrocannabinol (THC), and cannabinol (CBN). The steps from CBD to THC to $\mathrm{CBN}$ represent the biosynthetic pathway in the plant. THC is an optically active resinous material that is very lipid-soluble but water-insoluble; these physical properties make pharmacological investigations difficult, since various nonpolar solvents must be used. Although many other materials have been found in this plant, the cannabinoids are unique to it and THC is the only one with appreciable mental affects [10].

The pharmacological actions of THC result from its binding to the cannabinoid receptors $\mathrm{CB} 1$ and $\mathrm{CB} 2$ located in the brain. These specialized receptors in the brain are for endogenous cannabinoids manufactured by the body such as anandamide, 2-arachidonyl glyceride (2-AG), and other related compounds. These cannabinoids have a natural role in pain modulation, control of movement, and memory. The natural role of cannabinoids in immune systems remains unclear. The brain develops tolerance to cannabinoids and animal research demonstrates the potential for dependence, but this potential is observed under a narrower range of conditions than exist for benzodiazepines, opiates, cocaine, or nicotine. [10]

THC is biotrans formed in the liver to 11-OH-THC and carboxy-THC, the main metabolite found in urine $[4,5]$. Cannabinnoids present a high lipid/water partition coefficient. Thus, they may be stored in body fat and slowly excreted with urine. They inhibited the liberation of acetylcholine in the hippocampus, which is the region of Central Nerve System (CNS) responsible for cognitive activities, such as learning and memory. Noradrenalin liberation is also inhibited in the regions of cerebral cortex and cerebellum, which are responsible for alertness and motor co-ordination, respectively $[4,6,7]$.

Cannabis is often portrayed as a substance that has detrimental effects on performance. Cannabis decreases coordination, distorts spatial perception and alters perception and awareness of the passage of time [8-12]. Steadward and 


\section{International Journal of Science and Research (IJSR) \\ ISSN (Online): 2319-7064 \\ Index Copernicus Value (2013): 6.14 | Impact Factor (2015): 6.391}

Singh $[8,13]$ found that cannabis smoking did not increase vital capacity or grip strength, and Renaud and Cormier found maximal exercise performance in 12 cyclists reduced from 16 to 15 minutes at 10 minutes after smoking a THC $1.7 \%$ cigarette. However, in this study vasodilation and bronchodilation were increased, suggesting that cannabis could also improve oxygenation to the tissues. Furthermore, hotlines developed in support of doped athletes report performance-enhancing capabilities (WADA, unpublished observations). Cannabis is presented as a drug that has significant positive effects in sports, such as improvement of vision for goalkeepers and muscle relaxation [8].

Smoked cannabis can decrease anxiety, fear, depression and tension [8, 10]. THC is anxiolytic at low doses, [14] the doses reportedly consumed by athletes [15]. Animal studies also addressed cannabinoid effects on aversive responses. Interfering with the hydrolysis or uptake of endocannabinoids reduced anxiety-like behaviours without motor impairment in rodents, [16-18] and CB1 knockout mice exhibited increased anxiety-like behaviour. In human volunteers, THC and cannabis also increased impulsive responses leading to more risk-taking behaviour but without affecting decision making [20, 21]. In this regard, and from a sports perspective, Furthermore, cannabinoids play a major role in the extinction of fear memories by interfering with learned aversive behaviours [8, 22-24]. Athletes who experienced traumatic events in their sports career could benefit from such an effect. For these reasons, Wagner [25] described cannabis as ergogenic. The endocannabinoid system is also involved in the modulation of mood. Animal studies demonstrate antidepressant-like effects in models based on inescapable or chronic stress [8, 17, 26, 27]. In adolescents and young adults, cannabis also helps in coping with negative mood and emotional distress [28-30]. Catlin and Murray [8] indicated that cannabis could be performance enhancing in sports that require greater concentration. Iven [8] noted that athletes use cannabis for relief of anxiety and stress, and perhaps to reduce muscle spasm [8]. Saugy et al. [15] suggested that athletes were mainly motivated to use cannabis due to its effects on relaxation and well-being, promoting better sleep [8].

Much additional research is needed to determine the effects of cannabis on athletic performance. The endocannabinoid system was discovered in the 1980s, and each year since this discovery we learn more about cannabinoid pharmacology. Clearly, cannabis induces euphoria, improves selfconfidence, induces relaxation and steadiness and relieves the stress of competition. Cannabis improves sleep and recovery after an event, reduces anxiety and fear and aids the forgetting of negative events such as bad falls and so forth. Cannabis increases risk taking and this perhaps improves training and performance, yielding a competitive edge. Cannabis increases appetite, yielding increased caloric intake and body mass. Cannabis enhances sensory perception, decreases respiratory rate and increases heart rate; increased bronchodilation may improve oxygenation of the tissues. Finally, cannabis is an analgesic that could permit athletes to work through injuries and pain induced by training fatigue [8].
In conclusion, although much more scientific information is needed, based on current animal and human studies as well as on interviews with athletes and information from the field, cannabis can be performance enhancing for some athletes and sports disciplines [8].

\section{Materials and Methods}

In our study included 120 randomly selected students at the Sports University in age from 18 to 25 years in different disciplines - football, volleyball, athletics, boxing, wrestling and others. All 120 students were screened with Drug Use Disorders Identification Test - DUDIT. 50 had a positive urine test for cannabinoids.

We screened 120 randomly selected students of Medicine aged between $18-25$. Circulated DUDIT during the lecture and asked students if desired to participate in the study to record their telephone numbers. The control group was 19 medical students with positive urine test for cannabinoids in a comparable ratio for age range $18-25$ years.

First screening two groups of students at the National Sports Academy in Sofia and Medical University in Pleven using DUDIT

The study included men with $\geq 6$ points DUIT and women $\geq$ 2 points DUDIT. These limits on both scales are methodologically consistent with our designs and other similar studies. Then students were asked to provide urine test for use of cannabinoids. We have designed a questionnaire containing six closed questions. All participants completed self-administered questionnaire.

1) Name

2) Age

3) Gender

4) Are you active athletes?

5) Use of cannabinoids in the last 12 months.

6) Why use cannabinoids:

a) For relax, to forget problems, to alleviate stress

b) For pleasure, to enjoy its psychoactive effects

c) To spend good time with friends, to have fun in parties

This research uses sociological methods of gathering information - interviews and questionnaire. None of the planned study procedures puts at risk the life and health of patients. The processing of the received data for the study was performed with specialized statistical software packages STATGRAPHICS; SPSS and EXCEL for Windows. Statistical significance was ascertained by t-test, curve fitting, or ANOVA, as appropriate. The significance of the results, findings and conclusions determined at $\mathrm{p}<0,05$.

\section{Results and Discussion}

Of total screened 120 students in the Sports University 50 $(41,7 \%)$ have used cannabis in the last 12 months. Of the 50 active student athletes with use of cannabis $18(36 \%)$ are women and $32(64 \%)$ are men. In the control group of students at the Medical University Pleven 19 (15,8\%) have 


\section{International Journal of Science and Research (IJSR) \\ ISSN (Online): 2319-7064}

Index Copernicus Value (2013): 6.14 | Impact Factor (2015): 6.391

used cannabis in the last 12 months $-7(36,8 \%)$ women and $12(63,2)$ men.

We found a statistically significant difference between students from the Sports University $(41,7 \%)$ and students $(15,8 \%)$ at the Medical University, Pleven used cannabis in the last 12 months.

In the group of athletes found significantly higher proportion of men $(64 \%)$ than women $(36 \%)(\mathrm{p}<0,001)$. In the group of medical students was not significantly different by gander $(\mathrm{p}>0,05)$.

General in the group of athletes $16(32 \%)$ use cannabinoids for relax, to forget problems or to alleviate stress. Among students at the National Sports Academy 4 (22\%) women and $12(38 \%)$ men use cannabis for relaxation $(\mathrm{p}>0,05)$.

Among the group of medical students 15 (79\%) use cannabis for relax, to forget problems or to alleviate stress, gender distribution was as follows $6(86 \%)$ of women and $9(75 \%)$ of men $(\mathrm{p}>0,05)$.

We found significantly higher proportion of medical students who use cannabis for relaxation (79\%) compared to athletes $(32 \%)(\mathrm{p}<0,05)$.

We did not find statistically significant difference between the two studied groups of students who use cannabis for pleasure, to enjoy its psychoactive effects $-1(5 \%)$ of the medical students and $8(16 \%)$ athlete, as well as by gender $(\mathrm{p}>0,05) .26(52 \%)$ of students in the Sports University use cannabis to have fun at parties, this percentage is significantly higher compared to the group of medical students $-3(16 \%)(\mathrm{p}<0,05)$.

\section{Conclusion}

The present data result from a survey carried out on students from two major Sports University and Medical University in Bulgaria. Students in various sports disciplines significantly more frequently use cannabis $(41,7 \%)$, compared with medical students $(15,8 \%)$. The number of men is higher in both studied groups. An interesting fact is that the cause of cannabis use athletes indicate impaired social adaptation and desire to have fun at parties (52\%), and medical students looking for the effect of relaxation and reducing stress (79 $\%)$.

Results obtained in our study give rise to future studies

\section{References}

[1] Karch S., Bollmann M., et al. Drug abuse handbook. Sport. 2007; 714-716.

[2] Drumer OH., The forensic pharmacology of drugs of abuse. London: Arnold, 2001

[3] Frank M., Rosenthal E., Marijuana growers guide. Berkeley (CA): And/Or Press, 1978

[4] Campos D., Yonamine M., Mareau R. Marijuana as Doping in Sports. Sports Med 2003; 33 (6): 395-399
[5] Wall ME, Brine DR, Pit CG, et al. Identification of delta 9-tetrahydrocannabinol and metabolites in man. $\mathbf{J}$ Am Chem Soc 1972; 94 (24): 8579-81

[6] Porter AC, Felder CC. The endocannabinoid nervous system: unique opportunities for therapeutic intervention. Pharmacol Ther 2001; 90: 45-60

[7] Pertwce RG. Pharmacology of cannabinoid CB1 and CB2 receptors. Pharmacol Ther 1997; 74 (2): 129-80

[8] Huestis M., Mazzoni I., Rabin O., Cannabis in Sport: Anti-Doping Perspective. Sport Med. 2011 November 1; 41(11): 949-966

[9] Matthew RJ, Wilson WH, Turkington TG, et al. Cerebellar activity and disturbed time sense after THC. Brain Res. 1998; 797:183-189. [PubMed: 9666122]

[10] Ashton CH. Pharmacology and effects of cannabis: a brief review. $\mathrm{Br} \mathrm{J}$ Psychiatry. 2001; 178:101-106 [PubMed: 11157422]

[11] Wachtel SR, ElSohly MA, Ross SA, et al. Comparison of the subjective effects of delta(9)tetrahydrocannabinol and marijuana in humans. Psychopharmacology (Berl). 2002; 161:331-339. [PubMed:12073159]

[12] Grotenhermen F. The toxicology of cannabis and cannabis prohibition. Chem Biodivers. 2007;4:17441769. [PubMed: 17712818]

[13] Steadward RD, Singh M. The effect sof smoking marihuana on physical performance. Med Sci Sports. 1975; 7:309-311. [PubMed: 1235156]

[14] Berrendero F, Maldonado R. Involvement of the opioid system in the anxiolytic-like effects induced by delta(9)tetrahydrocannabinol. Psychopharmacology (Berl). 2002; 163:111-117. [PubMed: 12185408]

[15] Saugy M, Avois L, Saudan C, et al. Cannabis and sport. Br J Sports Med. 2006; 40(Suppl. 1):13-15.

[16] Bortolato M, Campolongo P, Mangieri RA, et al. Anxio-lytic-like properties of the anadamide transport inhibitor AM404. Neuropsychopharmacology. 2006; 31:2652-2659. [PubMed: 16541083]

[17] Naidu PS, Varel SA, Ahn K, et al. Evaluation of fatty acid amide hydrolase inhibition in murine models of emotionality. Psychopharmacology (Berl). 2007; 192:61-70. [PubMed: 17279376]

[18] Moreira FA, Aguiar DC, Guimaraes FS. Anxiolytic-like effect of cannabidiol in the rat Vogel conflict test. Prog Neuropsychopharmacol Biol Psychiatry. 2006; 30:1466-1471. [PubMed: 16876926]

[19] Haller J, Varga B, Ledent C, et al. Context-dependent effects of CB1 cannabinoid gene disruption on anxietylike and social behaviour in mice. Eur J Neurosci. 2004; 19:1906-1912. [PubMed: 15078564]

[20] McDonald J, Schleifer L, Richards JB, et al. Effects of THC on behavioral measures of impulsivity in humans. Neuropsychopharmacology. 2003; 28:1356-1365. [PubMed: 12784123]

[21] Lane SD, Cherek DR, Tcheremissine OV, et al. Acute marijuana effects on human risk taking. Neuropsychopharmacology. 2005; 30:800-809.

[22] Marsicano G, Wotjak CT, Azad SC, et al. The endogenous cannabinoid system controls extinction of aversive memories. Nature. 2002; 418:530-534. [PubMed: 12152079]

[23] Chhatwal JP, Davies M, Maguschak KA, et al. Enhancing cannabinoid neurotransmission augments the extinction of conditioned fear. 


\section{International Journal of Science and Research (IJSR) \\ ISSN (Online): 2319-7064}

Index Copernicus Value (2013): 6.14 | Impact Factor (2015): 6.391

Neuropsychopharmacology. 2005; 30:516-524. [PubMed: 15637635]

[24]Lutz B. The endocannabinoid system and extinction learning. Mol Neurobiol. 2007; 36:92-101. [PubMed: 17952654]

[25] Wagner JC. Abuse of drugs used to enhance athletic performance. Am J Hosp Pharm. 1989; 46:2059-2067. [PubMed: 2683762]

[26] Bambico FR, Katz N, Debonnel G, et al. Cannabinoids elicit antidepressant-like behavior and activate serotonergic neurons through the medial prefrontal cortex. J Neurosci. 2007; 27:11700-11711. [PubMed: 17959812]

[27] Bortolato M, Mangieri RA, Fu J, et al. Antidepressantlike activity of the fatty acid amide hydrolase inhibitor URB597 in a rat model of chronic mild stress. Biol Psychiatry. 2007; 62:1103-1110. [PubMed: 17511970]

[28] Chabrol H, Duconge E, Casas C, et al. Relations between cannabis use and dependence, motives for cannabis use and anxious, depressive and borderline symptomatology. Addict Behav. 2005; 30:829-840. [PubMed: 15833585]

[29] Simons JS, Gaher RM, Correia CJ, et al. An affectivemotivational model of marijuana and alcohol problems among college students. Psychol Addict Behav. 2005; 19:326-334. [PubMed: 16187813]

[30]Bonn-Miller MO, Zvolensky MJ, Bernstein A. Marijuana use motives: concurrent relations to frequency of past 30-day use and anxiety sensitivity among young adult marijuana smokers. Addict Behav. 2007; 32:49-62. [PubMed: 16647822]

Volume 5 Issue 6, June 2016 www.ijsr.net 